\title{
Risk factors for breast cancer in China: similarities and differences with western populations
}

Federica Turati ${ }^{1,2}$, Carlo La Vecchia ${ }^{1,2}$

1Dipartimento di Epidemiologia, Istituto di Ricerche Farmacologiche "Mario Negri", Milan, Italy

2Dipartimento di Medicina del Lavoro, Università degli Studi di Milano, Milan, Italy

Submitted: 5 May 2012

Accepted: 7 May 2012

Arch Med Sci 2012; 8, 2: 179-182

DOI: $10.5114 /$ aoms.2012.28542

Copyright $\odot 2012$ Termedia \& Banach

The study by Xu et al., reported in this issue of the Archives of Medical Science, is a large original study on breast cancer risk factors in China, a country with low breast cancer incidence $[1,2]$. The study shows results from the project of breast cancer prediction (BCPC) in China, aiming to screen breast cancer risk factors among Chinese women and predict individual risk of breast cancer through established risk factors. It is a multicentric hospital-based case-control study, carried out in 14 hospitals in 8 provinces of China, and, from January to July 2008, recruited 416 women aged 30 to 65 years with incident breast cancer and 1156 healthy women.

We are not commenting upon stress anticipation, which goes beyond our area of expertise. Apart from this, results from the BCPC study are only partly in agreement with those from studies from Western Countries, thus suggesting a somewhat different pattern of risk factors for the Chinese population.

In particular, the study confirms the role of history of benign breast disease biopsy in breast cancer [2], estimating an adjusted odds ratio (OR) of 1.68 (95\% confidence interval $-\mathrm{Cl}-1.19-2.38)$.

Moreover, in agreement with most literature on breast cancer and family history of breast cancer [3-6], the BCPC study found a positive, though not significant, association between having a first degree-relative affected by breast cancer and the risk of breast cancer $(\mathrm{OR}=1.66,95 \% \mathrm{Cl}$ : 0.77-3.59).

Reproductive and hormonal factors play a central role in the etiology of breast cancer [7]. Earlier menarche and later menopause are well established risk factors for the development of breast cancer [8-10], being responsible for a prolonged lifetime exposure to endogenous hormones [11]. The risk of breast cancer decreases by about 5\% with each 1-year delay in menarche [11-14] and, on average, the risk increases by about $2.7 \%$ for each year menopause is delayed [13]. The positive association between age at menarche and breast cancer risk found by Xu et al., with an OR of 1.41 (95\% Cl: 1.07-1.87) for women with menarche at age 14 years or more, is inconsistent with the overall evidence. The increased risk associated to menopause was also controversial, given the similar mean age at menopause among cases and controls (i.e., 48.89 vs. 49.33 years, respectively). Likewise, the Japan Collaborative Cohort Study, prospectively examining more than 38,000 women in a traditionally low-risk population as Japan, found no association between breast cancer and age at menarche and at

\author{
Corresponding author: \\ Prof. Carlo La Vecchia \\ Dipartimento \\ di Epidemiologia \\ Istituto di Ricerche \\ Farmacologiche \\ "Mario Negri" \\ Via La Masa 19 \\ 20156 Milan, Italy \\ Phone: +390239014527 \\ Fax: +390233200231 \\ E-mail: \\ carlo.lavecchia@marionegri.it
}


menopause [8]. Still, accurate adjustment for age and socioeconomic factors is required for any inference on these factors.

In the BCPC study, parous women represent almost the totality of cases and controls, and parity tended to be uniformly low. Likewise, the apparent uniformity of age at first birth may explain the limited association with this well recognized risk factor [15-17]. No meaningful differences emerged between women with and without breast cancer in terms of number of live births and age at first live birth. Conversely, epidemiological literature consistently found that a younger age at first full-term pregnancy is associated to a lower lifetime risk of breast cancer, and that a higher number of births is related to a lower risk [2].

A protective effect of lactation on breast cancer has been reported by several studies [3], including the pooled analysis by the Endogenous Hormones and Breast Cancer Collaborative Group, which found that lifetime duration of breastfeeding was associated to a significant reduction in breast cancer risk among parous women, with a relative risk (RR) decreasing by $4.3 \%$ for every 12 months of breastfeeding [18]. Data in the BCPC study are however inadequate to materially contribute to the issue.

There is definite evidence that abortions are unrelated to excess risk of breast cancer $[19,20]$. A recent pooled analysis of 53 studies carried out in 16 countries found no association between spontaneous abortion and breast cancer, but a moderate protection for induced abortion [20]. However, when the analysis was restricted to studies with a prospective design, the risk of breast cancer did not differ significantly according to the number or timing of either type of abortion. The null association reported by Xu et al. is therefore in line with the most recent literature.

Evidence on the association between oral contraceptive $(O C)$ use and breast cancer indicates a modest increased risk, however restricted to current or recent use, or the absence of any association after 5 years or more since stopping [21-24]. Moreover, consistent findings from observational studies and randomized trials showed an increased breast cancer risk among women using combined estrogen-progestogen therapy in menopause [25-27]. The risk increases with increasing duration of use but decreases after cessation, leveling off after 5 years since stopping postmenopausal hormone use [25]. Crude results by Xu et al. were apparently in line with the overall evidence, with about $5.6 \%$ of cases and $3.9 \%$ of controls reporting OC use, and about $5.4 \%$ of cases and $2.5 \%$ of controls reporting hormone replacement therapy use; however the data were inadequate to perform detailed analyses of such relations by duration and timing of exposure, including time since stopping, which is the key factor for these variables.
The BCPC study found an excess risk of breast cancer among overweight/obese subjects. After adjustment for selected risk factors, including menopausal status, the OR for body mass index $(\mathrm{BMI}) \geq 24 \mathrm{~kg} / \mathrm{m}^{2}$ as compared to $\mathrm{BMI}<24 \mathrm{~kg} / \mathrm{m}^{2}$ was 4.07 (95\% Cl: 2.98-5.55). It is well known that the relation between $\mathrm{BMI}$ and breast cancer depends on menopausal status, with an inverse association among premenopausal women [3, 28-30], likely due to a more frequent anovulation in obese [31-33], and a moderate direct association among postmenopausal women [34]. Body mass index increases postmenopausal breast cancer risk mainly through elevated levels of circulating estrogens, particularly estradiol, in overweight women [34]. After menopause, adipose tissue is the major source of estrogen; moreover, overweight women have low levels of sex-hormone-binding globulin, resulting in a higher level of bio-available estrogens [34, 35]. $\mathrm{Xu}$ et al. investigated the association between BMI and breast cancer with no distinction between pre and postmenopausal status; thus the estimated OR for overweight women may underestimate the real association in postmenopausal women. Nonetheless, Xu et al. found an increased OR of about 4-fold for $\mathrm{BMI} \geq 24 \mathrm{~kg} / \mathrm{m}^{2}$, somewhat higher than expected on the basis of accumulated evidence on such relation in postmenopausal women [2, 3, 34-36]. In a pooled analysis of three Italian case-control studies, including a total of 3108 postmenopausal breast cancer patients and 2604 controls, ORs for successive BMI quintiles ranged from 1.2 to 1.4 , as compared to the lowest quintile, and the association was stronger among elderly women [36]. A pooled analysis from the Endogenous Hormones and Breast Cancer Collaborative Group, including data from eight prospective studies of postmenopausal women, for a total of 624 case subjects and 1669 control subjects, found ORs of 1.17, 1.50, 1.78, and 1.50 for successive categories of BMI, as compared to $\mathrm{BMI}<22.5 \mathrm{~kg} / \mathrm{m}^{2}$ [35]. It has been suggested that the relation between weight and risk of breast cancer in low risk areas, as China, may be different from that observed in Western countries, with a lack of association for premenopausal breast cancer and a stronger association for postmenopausal breast cancer $[2,37]$. Results from the BCPC study are in agreement with this hypothesis, and suggest a substantial excess risk for overweight women in a population with a low prevalence of overweight and among relatively young women (mean age was around 46 years for both cases and controls). Not surprisingly, therefore, the RR appears to be particularly elevated in overweight women, though the absolute risk and the population attributable risk [38] are not necessarily greater in Chinese than in Western populations. 
Alcohol intake is the most consistent dietary factor related to breast cancer [39-41]. Heavy alcohol intake, defined as the consumption of 3 or more drinks/day, was found to be associated with an increased risk of breast cancer by $40-50 \%$ [40]. For light drinking ( $\leq 1$ drink/day), a significant increase risk of the order of $4 \%$ has been estimated from a meta-analysis updated to November 2011 and based on 113 studies [40]. From individual data from 53 epidemiological studies of breast cancer, the Collaborative Group on Hormonal Factors in Breast Cancer found that, compared with non drinker women, the RR of breast cancer was $1.32(95 \% \mathrm{Cl}$ : 1.19-1.45) for women drinking 35-44 g of alcohol/day, and 1.46 (95\% Cl: 1.33-1.61) for those drinking $\geq 45 \mathrm{~g} /$ day, with a RR of breast cancer increasing by about $7 \%$ for each additional $10 \mathrm{~g} /$ day of alcohol intake [41]. Conversely, a recent case-control study conducted in China on more than 1000 incident breast cancer cases found an inverse association with low-to-moderate alcohol intake [42]. Xu et al. reported a null association between alcohol drinking and breast cancer risk, although the low prevalence of women who reported to drink alcohol in the BCPC study (about $9 \%$ of both cases and controls) do not allow to explore the relation in detail.

The possible effect of smoking on breast cancer risk has been investigated in a large number of studies [41]. Globally, data provided evidence that cigarette smoking is not associated with an appreciably increased breast cancer risk, as also emerged in the BCPC study.

One of the limits of the study by Xu and et al. is the lack of information on hormone receptor status. Recent epidemiological evidence suggests that the etiology of hormone receptor defined breast cancers may be heterogeneous [43-45]. In a recent systematic review collecting information on 31 studies, delayed childbearing and nulliparity were associated with increased risk of developing estrogen receptor $(E R)+$ breast cancers but not $E R$ - breast cancers, whereas early age at menarche and postmenopausal obesity were more consistently associated with increased risk of hormone receptorpositive than hormone receptor-negative tumors [43]. In 2006, a meta-analysis focused on reproductive factors found that the protective effect of parity and early age at first birth was confined to $E R+/$ progesterone receptor $(P R)+$ cancers, while that of late age at menarche was significant in both subtypes of breast cancer, although stronger for $E R+/ P R+$ than ER-/PR- cancers [44]. On the other hand, breastfeeding [43, 44], alcohol, smoking, family history of breast cancer, and premenopausal obesity [43] were similarly associated with both hormone receptor-defined breast cancers. Although it has been suggested that ER/PR status varies among racial groups and results from these reviews
$[43,44]$ were derived from studies conducted predominantly on Western populations, comparable findings were obtained by the Shanghai Breast Cancer Study [45]. In studies focused on breast cancer as a single entity, as that by Xu et al., some associations restricted to a breast cancer subtype could be diluted or masked.

Still, the BCPC study is an important original contribution towards our quantification of breast cancer risk factors.

\section{Acknowledgments}

This work was supported by the Italian Association for Cancer Research (AIRC), Milan, Italy (grant number: 10068).

\section{References}

1. Xu YL, Sun Q, Shan GL. A case-control study on risk factors of breast cancer in China. Arch Med Sci 2012; 8: 303-9.

2. Colditz GA, Baer HJ, Tamimi RM. Breast cancer. In: Schottenfeld D, Fraumeni JF Jr (eds). Cancer epidemiology and prevention. 3rd ed. Oxford University Press, New York 2006; 995-1012.

3. Hankinson RT, Tamimi R, Hunter D. Breast cancer. In: Adami HO, Hunter D, Trichpoulos D (eds). Cancer epidemiology. 2nd ed. Oxford Universiy Press, New York 2008; 403-45.

4. Pharoah PD, Day NE, Duffy S, Easton DF, Ponder BA. Family history and the risk of breast cancer: a systematic review and meta-analysis. Int J Cancer 1997; 71: 800-9.

5. Negri E, Braga C, La Vecchia C, Franceschi S, Parazzini F. Family history of cancer and risk of breast cancer. Int J Cancer 1997; 72: 735-8.

6. Collaborative Group on Hormonal Factors in Breast Cancer. Familial breast cancer: collaborative reanalysis of individual data from 52 epidemiological studies including 58,209 women with breast cancer and 101,986 women without the disease. Lancet 2001; 358: 1389-99.

7. Collaborative Group on Hormonal Factors in Breast Cancer. Endogenous sex hormones and breast cancer in postmenopausal women: reanalysis of nine prospective studies. J Natl Cancer Inst 2002; 94: 606-16.

8. Tamakoshi K, Yatsuya H, Wakai K, et al. Impact of menstrual and reproductive factors on breast cancer risk in Japan: results of the JACC study. Cancer Sci 2005; 96: 57-62.

9. Nagata C, Hu YH, Shimizu H. Effects of menstrual and reproductive factors on the risk of breast cancer: metaanalysis of the case-control studies in Japan. Jpn J Cancer Res 1995; 86: 910-5.

10. Gao YT, Shu XO, Dai Q, et al. Association of menstrual and reproductive factors with breast cancer risk: results from the Shanghai Breast Cancer Study. Int J Cancer 2000; 87: 295-300.

11. Bernstein L. Epidemiology of endocrine-related risk factors for breast cancer. J Mammary Gland Biol Neoplasia 2002; 7: 3-15.

12. Hsieh CC, Trichopoulos D, Katsouyanni K, Yuasa S. Age at menarche, age at menopause, height and obesity as risk factors for breast cancer: associations and interactions in an international case-control study. Int J Cancer 1990; 46: 796-800.

13. Kelsey JL, Gammon MD, John EM. Reproductive factors and breast cancer. Epidemiol Rev 1993; 15: 36-47. 
14. Decarli A, La Vecchia C, Negri E, Franceschi S. Age at any birth and breast cancer in Italy. Int J Cancer 1996; 67: 187-9.

15. La Vecchia C, Decarli A, Parazzini F, et al. General epidemiology of breast cancer in northern Italy. Int J Epidemiol 1987; 16: 347-55.

16. La Vecchia C, Negri E, Boyle P. Reproductive factors and breast cancer: an overview. Soz Praventivmed 1989; 34: 101-7.

17. Trichopoulos D, Hsieh CC, MacMahon B, et al. Age at any birth and breast cancer risk. Int J Cancer 1983; 31: 701-4.

18. Collaborative Group on Hormonal Factors in Breast Cancer. Breast cancer and breastfeeding: collaborative reanalysis of individual data from 47 epidemiological studies in 30 countries, including 50302 women with breast cancer and 96973 women without the disease. Lancet 2002; 360: 187-95.

19. Tavani A, La Vecchia C, Franceschi S, Negri E, D'Avanzo B, Decarli A. Abortion and breast cancer risk. Int J Cancer 1996; 65: 401-5.

20. Collaborative Group on Hormonal Factors in Breast Cancer. Breast cancer and abortion: collaborative reanalysis of data from 53 epidemiological studies, including 83,000 women with breast cancer from 16 countries. Lancet 2004; 363: 1007-16.

21. La Vecchia C, Negri E, Franceschi S, et al. Oral contraceptives and breast cancer: a cooperative Italian study. Int J Cancer 1995; 60: 163-7.

22. Hunter DJ, Colditz GA, Hankinson SE, et al. Oral contraceptive use and breast cancer: a prospective study of young women. Cancer Epidemiol Biomarkers Prev 2010; 19: 2496-502.

23. Collaborative Group on Hormonal Factors in Breast Cancer. Breast cancer and hormonal contraceptives: collaborative reanalysis of individual data on 53297 women with breast cancer and 100239 women without breast cancer from 54 epidemiological studies. Lancet 1996; 347: 1713-27.

24. Rosenberg L, Zhang Y, Coogan PF, Strom BL, Palmer JR. A case-control study of oral contraceptive use and incident breast cancer. Am J Epidemiol 2009; 169: 473-9.

25. Collaborative Group on Hormonal Factors in Breast Cancer. Breast cancer and hormone replacement therapy: collaborative reanalysis of data from 51 epidemiological studies of 52,705 women with breast cancer and 108,411 women without breast cancer. Lancet 1997; 350: 1047-59.

26. La Vecchia C. Estrogen and combined estrogen-progestogen therapy in the menopause and breast cancer. Breast 2004; 13: 515-8.

27. Pelucchi C, Levi F, La Vecchia C. The rise and Fall in menopausal hormone therapy and breast cancer incidence. Breast 2010; 19: 198-201.

28. Tavani A, Gallus S, La Vecchia C, et al. Risk factors for breast cancer in women under 40 years. Eur J Cancer 1999; 35: 1361-7.

29. Franceschi S, Favero A, La Vecchia C, et al. Body size indices and breast cancer risk before and after menopause. Int J Cancer 1996; 67: 181-6.

30. Hunter DJ, Willett WC. Diet, body size, and breast cancer. Epidemiol Rev 1993; 15: 110-32.

31. Pike MC, Krailo MD, Henderson BE, Casagrande JT, Hoel DG. 'Hormonal' risk factors, 'breast tissue age' and the age-incidence of breast cancer. Nature 1983; 303: 767-70.

32. Pike MC. Age-related factors in cancers of the breast, ovary, and endometrium. J Chronic Dis 1987; 40 Suppl 2: 59S-69S.
33. La Vecchia C, Decarli A, di Pietro S, Franceschi S, Negri E, Parazzini F. Menstrual cycle patterns and the risk of breast disease. Eur J Cancer Clin Oncol 1985; 21: 417-22.

34. La Vecchia C, Giordano SH, Hortobagyi GN, Chabner B. Overweight, obesity, diabetes, and risk of breast cancer: interlocking pieces of the puzzle. Oncologist 2011; 16 726-9.

35. Collaborative Group on Hormonal Factors in Breast Cancer. Body mass index, serum sex hormones, and breast cancer risk in postmenopausal women. J Natl Cancer Inst 2003; 95: 1218-26.

36. La Vecchia C, Negri E, Franceschi S, et al. Body mass index and post-menopausal breast cancer: an age-specific analysis. Br J Cancer 1997; 75: 441-4.

37. Pathak DR, Whittemore AS. Combined effects of body size, parity, and menstrual events on breast cancer incidence in seven countries. Am J Epidemiol 1992; 135: 153-68.

38. Mezzetti M, La Vecchia C, Decarli A, Boyle P, Talamini R, Franceschi S. Population attributable risk for breast cancer: diet, nutrition, and physical exercise. J Natl Cancer Inst 1998; 90: 389-94.

39. Secretan B, Straif K, Baan R, et al. A review of human carcinogens. Part E: tobacco, areca nut, alcohol, coal smoke, and salted fish. Lancet Oncol 2009; 10: 1033-4.

40. Seitz HK, Pelucchi C, Bagnardi V, La Vecchia C. Epidemiology and pathophysiology of alcohol and breast cancer: update 2012. Alcohol Alcohol 2012; 47: 204-12.

41. Collaborative Group on Hormonal Factors in Breast Can cer. Alcohol, tobacco and breast cancer: collaborative reanalysis of individual data from 53 epidemiological studies, including 58,515 women with breast cancer and 95,067 women without the disease. Br J Cancer 2002; 87: 1234-45.

42. Zhang M, Holman CD. Low-to-moderate alcohol intake and breast cancer risk in Chinese women. $\mathrm{Br} J$ Cancer 2011; 105: 1089-95.

43. Althuis MD, Fergenbaum JH, Garcia-Closas M, Brinton LA, Madigan MP, Sherman ME. Etiology of hormone receptor-defined breast cancer: a systematic review of the literature. Cancer Epidemiol Biomarkers Prev 2004; 13: 1558-68.

44. Ma H, Bernstein L, Pike MC, Ursin G. Reproductive factors and breast cancer risk according to joint estrogen and progesterone receptor status: a meta-analysis of epidemiological studies. Breast Cancer Res 2006; 8: R43.

45. Bao PP, Shu XO, Gao YT, et al. Association of hormonerelated characteristics and breast cancer risk by estrogen receptor/progesterone receptor status in the Shanghai Breast Cancer Study. Am J Epidemiol 2011; 174: 661-71. 